\title{
Do Local Governments Engage in Strategic Property-Tax Competition?
}

\author{
by \\ Jan K. Brueckner \\ Department of Economics \\ and \\ Institute of Government and Public Affairs \\ University of Illinois at Urbana-Champaign \\ Champaign, IL 61820 \\ and \\ Luz A. Saavedra \\ Department of Economics \\ University of South Florida \\ Tampa, FL 33620
}

August 1997; Revised May 1998, November 1999

\begin{abstract}
This paper uses spatial econometric methods to investigate property-tax competition among local governments. The theoretical model is drawn from the literature on tax competition, in which local jurisdictions choose property-tax rates taking into account the migration of mobile capital in response to tax differentials. Using a "spatial lag" econometric model, the paper estimates the reaction function of the representative community, which relates the community's property-tax rate to its own characteristics and to the tax rates in competing communities. A nonzero reaction-function slope indicates the presence of strategic interaction in the choice of tax rates. The estimation uses cross-section data on property taxes and other socio-economic variables for cities in the Boston metropolitan area. The results, which are presented for two periods before and after imposition of Proposition $2 \frac{1}{2}$ (a tax limitation measure), indicate the presence of strategic interaction.
\end{abstract}




\title{
Do Local Governments Engage in Strategic Property-Tax Competition?
}

by

\author{
Jan K. Brueckner and Luz A. Saavedra*
}

\section{Introduction}

A long line of research in public finance analyzes fiscal interaction among governments. Fiscal interaction may be the result of benefit spillovers, where residents of one jurisdiction consume the public goods provided by neighboring jurisdictions. Alternatively, interaction may arise because of interjurisdictional mobility of the tax base. The early theoretical literature (Williams (1966), Pauly (1970), Oates (1972), and Boskin (1973)) analyzed interaction due to spillovers. Subsequent work has focused on interaction due to tax-base mobility, generating what has become known as the "tax competition" literature. In tax-competition models, jurisdictions finance provision of a public good with a tax on locally-employed capital. Capital is nationally fixed but moves among jurisdictions in response to tax-rate differentials, while community populations are typically immobile. In the competitive version of the model, first analyzed by Beck (1983), Wilson (1986), and Zodrow and Mieszkowski (1986), jurisdictions are small relative to the economy and thus are unable to affect the net-of-tax return to capital. As a result, tax rates in other jurisdictions are irrelevant, and strategic behavior is absent. When individual jurisdictions are large relative to the economy, each jurisdiction is able to alter capital's net return by varying its tax rate. In this case, which was first analyzed by Mintz and Tulkens (1986), Wildasin (1988a), and Bucovetsky (1991), the tax rates in other jurisdictions must be taken into account in a given jurisdiction's choice, leading to strategic behavior. Regardless of whether jurisdictions behave competitively or strategically, tax-competition models generate an important conclusion, namely that public goods are underprovided. The reason is that each community keeps its tax rate low in an attempt to preserve its tax base. See Wilson (1999) for an up-to-date survey of the literature. ${ }^{1}$

Despite the widespread theoretical interest in tax competition and other types of fiscal in- 
teraction, the empirical literature in this area is sparse. The pioneering study is by Case, Rosen and Hines (1993), who estimate an empirical model of strategic interaction among state governments in the U.S., viewing expenditures as the strategic variable. Their empirical specification is derived from a model of interstate benefit spillovers, and the estimation uses an approach borrowed from the spatial econometrics literature. Besley and Case (1995), Figlio, Kolpin and Reid (1997), Saavedra (1999), Shroder (1995), Smith (1997) also study fiscal interaction at the state level, with the latter four papers focusing on the choice of welfare benefits.

Only two previous studies investigate fiscal interaction among local governments using appropriate methodologies. Following the econometric approach of Case et al. (1993), Brueckner (1998) estimates a model of strategic interaction in the choice of growth-control measures by California cities. Heyndels and Vuchelen (1998) study the strategic choice of property taxes by Belgian municipalities, employing a similar methodology. ${ }^{2}$ The present paper complements the Heyndels-Vuchelen study by using city-level data from the U.S. to estimate a model of strategic property-tax competition. Although Heyndels and Vuchelen motivate their paper as a study of "tax mimicking" among nearby cities, the intent of the present study is to provide an indirect empirical test of tax-competition models, recognizing that local property taxes are the best real-world analog to the capital taxes analyzed in the existing theoretical studies.

The empirical analysis is designed to estimate the property-tax reaction function of a representative community. This function relates the community's property tax rate to its own characteristics and to the tax rates in competing jurisdictions. When tax rates are chosen strategically, taking account of capital movements among communities, the reaction function has a nonzero slope, indicating that changes in competitors' tax rates affect the given community's choice. The theory, however, shows that this slope can be either positive or negative, with the exact sign depending on parameter values. Alternatively, if strategic interaction is absent, then the reaction-function slope is identically zero. Thus, the empirical question of interest is whether the slope parameter is significantly different from zero. In this case, the absence of strategic interaction can be rejected as a null hypothesis. Despite the focus on statistical significance, the sign of the reaction-function slope is important in determining the comparative-static properties of the Nash equilibrium, as is shown in a simulation exercise 
based on the estimates.

The sample for the empirical work consists of 70 cities from the Boston metropolitan area. Massachusetts is a convenient empirical setting because cities and school districts are coterminous, so that a single property-tax rate applies within a city's boundaries, and because property taxes are the only important local revenue source. The Massachusetts setting is also interesting because it allows the test for strategic interaction to be carried out under two different property-tax regimes: before and after Proposition $2 \frac{1}{2}$, a property-tax limitation measure that took effect in 1981. A measure designed to limit property taxes should constrain the choices of local governments, reducing the extent of strategic interaction. This hypothesis is tested by estimating the model before (in 1980) and after (in 1990) the imposition of Proposition $2 \frac{1}{2}$.

Following earlier work, the econometric specification uses a spatial lag model. In such a model, a weight matrix aggregates the property-tax rates in competing communities into a single variable that appears on the right-hand side of the reaction function. Community characteristics also appear as explanatory variables, and their effect is to shift the intercept of the reaction function. The reduced form of this model is estimated via maximum likelihood techniques.

To motivate the empirical work, section 2 develops a theoretical model, which represents an adaptation of the standard tax-competition framework to our empirical setting. Section 3 develops the empirical model and describes the data. Sections 4 and 5 present the empirical results for 1980 and 1990, respectively. Section 6 describes the results of the simulation exercise, and Section 7 offers conclusions.

\section{A Model of Property-Tax Competition}

\subsection{Overview}

To understand our modeling approach, it is useful to review the evolution of research on the effects of competition among local governments. Starting with Tiebout (1956), a long line of research has shown that intergovernmental competition benefits consumers by generating a variety of public-good choices within a metropolitan area. This variety, which emerges as local governments compete to attract residents, leads to an equilibrium in which consumers 
efficiently self-select into different communities according to their demand for public goods. In contrast, the tax-competition literature has explored the "bad" side of intergovernmental competition, showing that each community sets its tax rate too low in an attempt to preserve its tax base.

Our view is that a realistic model of property-tax determination requires a blend of the Tiebout and tax-competition traditions. In such a model, consumers are mobile and self-select into homogeneous communities, which rely on property taxes to finance public goods. Since concern about capital flight leads to low tax rates, the equilibrium has efficient sorting of consumers across communities, but it exhibits a tendency toward underprovision of public goods.

To incorporate this view, we present a model where the standard assumption of homogeneous preferences, which characterizes all previous tax-competition models, is replaced by preference heterogeneity. Consumers, who consists of several discrete types, are assumed to sort into homogeneous communities according to their demand for public goods. Once sorted, the residents choose property taxes in the usual way, taking account of the depressing effect of the tax rate on the community's tax base. Because the number of communities is small, tax rates are chosen in strategic fashion. The resulting framework can be referred to as a strategic "Tiebout/tax-competition model." 3

As shown below, this model generates property-tax reaction functions in the usual way. However, the model carries important implications regarding the appropriate econometric methodology for estimating such functions. To see the issue, recall that community characteristics appear as shift variables on the right hand side of the estimated function. Although these characteristics are ultimately endogenous in a world of Tiebout sorting, our model implies that they may be treated as predetermined in analyzing the choice of tax rates. The reason is that consumers are assumed to sort initially, and then to choose property tax rates conditional on the achieved sorting. Given that each of the distinct consumer types (e.g., high, low, middle demanders) strictly prefers his own community, small variations in tax rates will not generate population movements. This in turn allows community characteristics to be treated as exogenous in estimating the reaction function. In the main part of their study, Heyndels 
and Vuchelen (1998) take this same approach.

A different conclusion would emerge in a model with a continuum of consumers differentiated by income, as in Epple and Romer (1991). In this case, communities are continuously stratified by income, and reaction functions again determine a Nash equilibrium in tax rates. Although such a model would generate an empirical framework nearly indistinguishable from the one used in this paper, community characteristics and tax rates would be jointly determined, requiring characteristics to be viewed as endogenous. The reason is that consumers at the stratification boundaries would be indifferent between communities, so that tax-rate changes would lead to population movements and resulting changes in average community incomes. Finding instruments to correct for the resulting endogeneity of community characteristics would be a formidable challenge. However, such a correction is unneeded if the empirical reality more closely resembles the one sketched above, where a discrete number of consumer types separate into homogeneous communities.

Another modeling issue concerns the proper assumption on the supply of capital to the regional economy, in our case the Boston metropolitan area. It could be argued that capital is supplied in perfectly-elastic fashion by the national market, making the competitive version of the tax-competition model appropriate and ruling out strategic interaction among Boston-area communities. However, there are reasons to think that capital supply is less than perfectly elastic, lending plausibility to the alternative assumption of a fixed stock of capital in the metropolitan area. First, the Boston area is well known as an incubator for high-technology industries, which suggests that investment in such industries is strongly tied to the area. In addition, other types of capital oriented toward serving the local population may be fixed in supply to the region. For example, the capital embodied in a given community's shopping centers, grocery stores, and other retail establishments may not leave the metropolitan area in response to an increase in the local property-tax rate, as a model with perfectly-elastic supply would predict. Instead, such capital may relocate to a nearby community within the area, so as to remain close to a targeted customer base. For both these reasons, the assumption of a fixed supply of capital is plausible, justifying its use in the analysis. 


\subsection{The model}

To begin developing the model, suppose for simplicity that the metropolitan area contains just two communities, and let $K_{i}$ denote the capital invested in community $i, i=1,2$. This capital is combined with a local fixed factor $P_{i}$ to produce a numeraire private good according to a constant-returns technology. The production function is given by $F\left(K_{i}, P_{i}\right)$, and its intensive form is written $f\left(k_{i}\right)$, where $k_{i}$ is capital per unit of the fixed factor. This factor is most conveniently viewed as the labor supplied by local workers, so that $P_{i}$ represents community $i$ 's population and $k_{i}$ is capital per worker. However, this assumption may be unrealistic since it implies that each community in the metropolitan area constitutes a separate labor market. Alternatively, $P_{i}$ could be viewed as the fixed land area devoted to private-good production, which would be owned by the local residents. For concreteness, the ensuing discussion adopts the labor interpretation of the fixed factor.

Property taxes are levied on the capital invested in each community, with $t_{i}$ denoting the tax per unit of capital in community $i$. The net-of-tax return then equals capital's marginal product less the tax, or $f^{\prime}\left(k_{i}\right)-t_{i}$. Since capital is mobile, net returns must be equalized across communities, so that

$$
f^{\prime}\left(k_{1}\right)-t_{1}=f^{\prime}\left(k_{2}\right)-t_{2}=\rho,
$$

where $\rho$ is the uniform net return. Given that the metropolitan area's capital stock is fixed at $\bar{K}$, the additional condition

$$
P_{1} k_{1}+P_{2} k_{2}=\bar{K}
$$

must also hold. Together, (1) and (2) determine $k_{1}, k_{2}$, and $\rho$ as functions of $t_{1}$ and $t_{2}$. It is easily shown that $\partial k_{i} / \partial t_{i}<0$ holds for $i=1,2$, indicating that higher taxes shrink community $i$ 's tax base as capital relocates to equalize net returns. The derivative $\partial \rho / \partial t_{i}$ is also negative, indicating that capital's net return is reduced by higher taxes.

For realism, the property tax is also levied on housing. To simplify the analysis, we assume that housing is produced using only land, with the capital input ignored. In addition, the quantity of residential land in the community, denoted $L_{i}$, is fixed, which means housing supply is perfectly inelastic. By appropriate choice of units of measurement for land, the tax 
per unit can be set equal to $t_{i}$, the rate on capital. Land's net-of-tax return is denoted $r_{i}$, so that its gross price is then $r_{i}+t_{i}$.

The residents of each community are assumed to be owner-occupiers, owning equal shares of the residential land. The land endowment per capita in community $i$ is $q_{i}^{*} \equiv L_{i} / P_{i}$. Also, as in the standard tax-competition model, ownership of the metropolitan area's capital stock is divided equally among all consumers, with individual endowments given by $k^{*} \equiv \bar{K} /\left(P_{1}+P_{2}\right)$.

As explained above, we assume that the sorting process generates communities with homogeneous preferences. Accordingly, let $U_{i}\left(x_{i}, q_{i}, z_{i}\right)$ denote the common utility function for residents of community $i$, where $x_{i}$ is private-good consumption, $q_{i}$ is housing consumption, and $z_{i}$ is consumption of a public good. Consumer income is the sum of the following components: the return to the fixed factor, $w_{i}=f\left(k_{i}\right)-k_{i} f^{\prime}\left(k_{i}\right)$, which is interpreted as wage income; the return to the capital endowment, $\rho k^{*}$; and the return to the residential land endowment, $r_{i} q_{i}^{*}$. Since consumers, as owner-occupiers, can be viewed as renting land from themselves, the budget constraint for a resident of community $i$ is then

$$
x_{i}=w_{i}+\rho k^{*}+\left(r_{i}-t_{i}\right) q_{i}^{*}-r_{i} q_{i} .
$$

In addition, assuming that the public good is a private good with a unit cost of one, the government's budget constraint is

$$
z_{i}=t_{i}\left(q_{i}^{*}+k_{i}\right)
$$

where the second expression is property-tax revenue per capita.

Because of fixed land supply and the absence of housing capital, the residential portion of the property tax functions as a lump-sum tax, so that the model ultimately behaves just like a standard tax-competition model. This follows because clearing of the housing market requires land consumption to equal the per capita endowment, so that $q_{i}=q_{i}^{*}$. While adjustment of $r_{i}$ ensures that this equality is satisfied, the net return then drops out of the budget constraint, with the last two terms in (3) reducing to $-t_{i} q_{i}^{*}$, a lump-sum tax. Substituting for $w_{i}$ in (3), 
and using (4), utility can then be written

$$
U_{i}\left[f\left(k_{i}\right)-k_{i} f^{\prime}\left(k_{i}\right)+\rho k^{*}-t_{i} q_{i}^{*}, q_{i}^{*}, t_{i}\left(q_{i}^{*}+k_{i}\right)\right]
$$

The residents of community choose $t_{i}$ to maximize (5), taking into account the effects of the tax rate on $k_{i}$ and $\rho$. In addition, the tax rate in the other community is viewed as parametric. Differentiating (5) with respect to $t_{i}$ and using (1), the first-order condition is

$$
\frac{U_{i z}}{U_{i x}}=\frac{k_{i}+q_{i}^{*}+\left(k_{i}-k^{*}\right) \frac{\partial \rho}{\partial t_{i}}}{k_{i}+q_{i}^{*}+t_{i} \frac{\partial k_{i}}{\partial t_{i}}}
$$

where the terms on the left are marginal utilities. The standard efficiency result in the literature can be seen by evaluating (6) in the symmetric case, where consumers have identical preferences and where community populations and residential land areas are equal. In this case, $t_{1}=t_{2}$ must hold in the Nash equilibrium, implying $k_{1}=k_{2}=k^{*}$. The right-hand side of (6) then reduces to $\left(k^{*}+q^{*}\right) /\left[k^{*}+q^{*}+t_{i}\left(\partial k_{i} / \partial t_{i}\right)\right]>1$, where $q^{*}$ is the common land endowment (recall $\left.\partial k_{i} / \partial t_{i}<0\right)$. Since the marginal rate of transformation between the private and public goods is unitary, this inequality implies that $z$ is underprovided. ${ }^{4}$ Note that (6) is identical to the standard formula in the literature when $q^{*}$ is set equal to zero.

Suppose now that population and land-area symmetry is preserved, but that residents of community 1 are high demanders of the public good, with low demanders living in community 2. In this case, the equilibrium is asymmetric, and it is determined by the joint solution of (6) for $i=1,2$, where different marginal rates of substitution appear on the left-hand sides. To see how the asymmetry arises, start at a symmetric low-demand equilibrium, and observe that the high demanders have an incentive to raise $t_{1}$ in order to spend more on the public good, viewing $t_{2}$ as parametric. Capital moves from community 1 to 2 in response, but tax revenue rises initially in community 1 because of the higher tax rate, satisfying the stronger demand for $z$. In the resulting Nash equilibrium, $t_{1}>t_{2}$ holds, implying $k_{1}<k_{2}$. This result can be proved formally by adapting the approach of Wilson (1991), who analyzes the asymmetry caused by intercommunity differences in factor endowments. 
This discussion suggests that in a strategic Tiebout/tax-competition model, high-demand communities have high property-tax rates and low capital stocks, while the reverse is true in low-demand communities. Thus, high-demand communities end up driving away business investment in pursuit of a high level of public spending. Brueckner (1999) establishes that the same conclusion holds in a Tiebout/tax-competition model based on competitive, rather than strategic, behavior.

\subsection{Reaction functions}

The tax rates $t_{1}$ and $t_{2}$ that emerge in the Nash equilibrium are located at the intersection of the reaction functions for communities 1 and 2 . To see the origin of these functions, let $i=1$ in $(6)$, and note that since $k_{1}$ depends on $t_{1}$ and $t_{2}$, the equation implicitly determines $t_{1}$ as a function of $t_{2}$, yielding community 1's reaction function. Community 2's function is found similarly.

Because estimation of reaction functions is the goal of the empirical work, it is useful to derive these functions for a special case. This example also illustrates an important point mentioned in the introduction, namely that reaction functions can either slope up or down. First, suppose that $f$ is quadratic, with $f\left(k_{i}\right)=\beta k_{i}-\gamma k_{i}^{2} / 2$, where $\beta, \gamma>0$. In addition, suppose that preferences are linear, with $U_{i}\left(x_{i}, q_{i}, z_{i}\right)=x_{i}+\tau_{i} q_{i}+\eta_{i} z_{i}$, where $\tau_{i}, \eta_{i}>0$. Then, (1) and (2) yield $k_{1}=k^{*}+\left(t_{2}-t_{1}\right) / 2 \gamma$, so that $\partial k_{1} / \partial t_{1}=-1 / 2 \gamma$. Substituting these results in (6) for $i=1$, and substituting $\eta_{1}$ on the left-hand side, the equation can be solved to yield community 1's reaction function. The function is linear and is written

$$
t_{1}=\frac{4 \gamma\left(1-\eta_{1}\right)\left(k^{*}+q^{*}\right)+\left(1-2 \eta_{1}\right) t_{2}}{1-4 \eta_{1}} .
$$

Since the second-order condition for the maximization problem requires $1-4 \eta_{1}<0$ or $\eta_{1}>$ $1 / 4$, the denominator of (7) is negative. Therefore, reaction function's slope, which equals $\left(1-2 \eta_{1}\right) /\left(1-4 \eta_{1}\right)$, negative when $1 / 4<\eta_{1}<1 / 2$ and positive when $\eta_{1}>1 / 2$. Thus, community 1 lowers (raises) its tax rate in response to an increase in $t_{2}$ when the marginal utility of the public good is small (large). Community 2's reaction function is generated by interchanging the 1 and 2 subscripts in (7), and the intersection between this function and (7) 
gives the Nash equilibrium. Figure 1 shows an equilibrium for the case where both reaction functions are upward sloping (the dotted line is discussed below).

If both preferences and populations differ across communities, (7) is replaced by

$$
t_{1}=\frac{\gamma\left(1-\eta_{1}\right)\left(k^{*}+q^{*}\right) / s_{1}^{2}+\left(1-\eta_{1} / s_{1}\right) t_{2}}{1-2 \eta_{1} / s_{1}}
$$

where $s_{1}=P_{2} /\left(P_{1}+P_{2}\right)$ equals the share of the metropolitan population living outside of community 1. The slope of the reaction function in (8) may again be positive or negative, depending on the magnitude of $\eta_{1}$ in relation to $s_{1}$. Generally, (8) shows that the position of the reaction function depends on community preferences and on the distribution of population within the metropolitan area, a dependence that will also hold in general.

This discussion shows that, with the exception of the knife-edge case where $\eta_{1}=s_{1}$, the reaction function slope in (8) is nonzero. As a result, the proper empirical test for the existence of strategic property-tax competition is a simple significance test on the estimated slope parameter. If the empirical results show that the slope is significantly different from zero, then the evidence is consistent with strategic behavior. Otherwise, the reaction function is flat, indicating the absence of strategic interaction in property-tax choices.

A final observation is that the key features of the Tiebout/tax-competition equilibrium are verified in the present special case. In particular, it can be shown that in any stable Nash equilibrium with equal populations, a community's tax rate depends on the strength of its demand for public goods, with $t_{1}>(<) t_{2}$ holding as $\eta_{1}>(<) \eta_{2}$. Thus, the high-demand community has a high tax rate and a low capital stock.

\section{The Empirical Model}

\subsection{General specification}

The property-tax reaction function given by (8) is the starting point for specification of the empirical model. This equation implies that community $i$ 's property-tax rate depends on tax rates in other communities, on its own preferences, and on the distribution of the metropolitan 
population. A simple empirical version of (8) may be written

$$
t_{i}=\phi \sum_{j \neq i} \omega_{i j} t_{j}+Z_{i} \theta+\epsilon_{i}
$$

In (9), the $\omega_{i j}, j \neq i$, represent a set of weights that aggregate the tax rates in other communities into a single variable, which has a scalar coefficient $\phi . Z_{i}$ is a vector containing the socio-economic characteristics of community $i$, which represent preferences and other factors affecting the demand for public goods ( $\theta$ is the corresponding coefficient vector). The error term is $\epsilon_{i}$, and it is assumed to be normally distributed with constant variance and to be independent across observations. Note that (9) may be viewed as a linear approximation to a more general nonlinear reaction function.

It is important to note that the weights in (13) are specified arbitrarily, and that a common slope parameter $\phi$ applies to the (weighted) tax rate in each competing community. More flexible specifications would be impossible to estimate. Although the weights are arbitrary, a variety of weighting schemes may be explored to allow different patterns of spatial interaction, as explained further below.

Repeating (9) for each community in the metropolitan area, the equation can be rewritten in matrix form as

$$
t=\phi W t+Z \theta+\epsilon,
$$

where $t$ is the vector of property-tax rates, $Z$ is the matrix of socio-economic characteristics, and $\epsilon$ is the error vector. Note that the diagonal elements of the weight matrix $W$ are zero and that a representative off-diagonal element is $\omega_{i j}$. In the econometrics literature, a model such as (10) is known as a spatial autoregressive, or spatial lag, model. In the present context, the "lag" parameter $\phi$ gives the slope of the reaction function.

The theoretical model implies that property-tax rates are jointly determined in a Nash equilibrium, and this simultaneity means that that the vector $W t$ on the right-hand side of (10) is endogenous. Because of its endogeneity, $W t$ is correlated with the error vector $\epsilon$, implying that ordinary least squares estimates of the parameters of (10) are inconsistent. This 
problem can be circumvented, however, by solving for the reduced form of (10). Assuming that $I-\phi W$ is invertible, the reduced form is

$$
t=(I-\phi W)^{-1} Z \theta+(I-\phi W)^{-1} \epsilon
$$

With simultaneity removed, (11) can be estimated using maximum likelihood techniques. ${ }^{5}$ Recall that in this estimation, the community-characteristics variables in $Z_{i}$ are treated as exogenous, as explained above.

As noted earlier, the variance-covariance matrix of the error vector $\epsilon$ is assumed to be proportional to the identity matrix, indicating that errors are independent across communities. Suppose this assumption is violated and that the errors instead exhibit spatial dependence, satisfying the relationship

$$
\epsilon=\lambda W \epsilon+v
$$

where $v$ is a well-behaved normal error vector. Such spatial dependence can arise when $\epsilon$ includes omitted variables not captured in $Z$, which are themselves spatially dependent. If spatial error dependence is ignored, estimation of (11) may yield a misleading estimate of the reaction-function slope $\phi$. For example, suppose that the true value of $\phi$ is zero but the errors are positively correlated across nearby communities. In this case, the true model is the "spatial error" model, which consists of $t=Z \theta+\epsilon$ and (12), with $\lambda>0$. Then, when (11) is the estimated using a distance-based $W$, the $\phi$ estimate is likely to be positive and significant, indicating that tax rates in nearby cities move together. Thus, uncorrected error dependence can give a false impression of strategic interaction when none in fact is occurring. Moreover, once the spatial lag model is estimated, a test for spatial error dependence may show its absence. The effects of error dependence may therefore be "hidden" in a spurious spatial lag parameter.

Several approaches exist for dealing with this problem. One is to estimate an expanded model consisting of (10) and (12), as is done by Case et al. (1993). However, reliable estimation of the separate parameters $\phi$ and $\lambda$, which perform similar roles in the model, may be difficult (see Anselin (1988), Anselin and Bera (1996), and Anselin, Bera, Florax and Yoon (1996)). 
Another approach is to separately test the hypotheses $\phi=0$ and $\lambda=0$ using the robust Lagrange multiplier tests developed by Anselin et al. (1996). In the case of $\phi$, the usual LM test would evaluate the increase in the likelihood function as $\phi$ diverges from zero, rejecting the hypothesis $\phi=0$ when the increase is sufficiently large. The problem is that, with nonseparability of the likelihood function, the distribution of the resulting test statistic depends on the value of $\lambda$, so that the test is invalid if the assumed value of $\lambda$ (e.g., zero) is incorrect. This problem is solved by adjusting the test statistic to account for the influence of $\lambda$, an adjustment that does not require knowledge of its true value. The same procedure can be used to construct a robust test of $\lambda=0$. Note that since both tests rely on estimates for the case $\phi=\lambda=0$, they can be carried out using the results of an OLS regression.

A third approach is to test the "common factor hypothesis," which must hold if the spatial error model is correct. Rejection of this hypothesis again suggests that evidence of strategic interaction is not spurious. ${ }^{6}$ The latter two approaches are pursued below, and additional diagnostic tests are carried out.

\subsection{Specification of the Weight Matrix}

Given that the weight matrix in (11) aggregates the tax rates of competing communities, its specification implicitly imposes a certain pattern of interaction. Our weighting schemes take into account the distances from a given community to its competitors, as well as the population sizes of the competitors.

Weights that vary inversely with distance are used to account for the possibility that capital is imperfectly mobile across communities within the metropolitan area. For example, because high-tech firms value proximity to similar businesses, a community attempting to add to an existing high-tech concentration will focus on tax rates in nearby communities, which constitute the relevant competition. The first of two distance-based weighting schemes is a simple contiguity scheme, which assigns a weight of one to cities within the Boston metropolitan area that share a border with the given city, and a weight of zero to other cities. The resulting weight matrix is denoted $W^{\text {cont }}$. The second scheme imposes a smooth distance decay, with weights given by $\omega_{i j}=1 / d_{i j}$ for $j \neq i$, where $d_{i j}$ is the distance between cities $i$ and $j$ (the resulting weight matrix is denoted $\left.W^{d}\right){ }^{7}$ Note that while $W^{\text {cont }}$ generates a simple sum of 
tax rates for the subset of cities that are adjacent to $i, W^{d}$ aggregates the tax rates of all cities in the metropolitan area, using weights that are inversely related to their distance from $i$. By convention, each weight matrix is row-normalized prior to estimation, so that the aggregation of competing tax rates actually takes the form of a weighted average.

Since the reaction-function slope in (8) depends on the distribution of population in the metropolitan area, population-based weighting schemes are also appropriate. The first weighting scheme gives competing city $j$ a weight equal to its population $P_{j}$, without regard to distance. The resulting weight matrix, whose representative element is $\omega_{i j}=P_{j}$, for $j \neq i$, is denoted $W^{P}$. Two additional schemes blend population and distance in generating weights, with the first assigning weight $P_{j}$ to cities $j$ that are contiguous to city $i$ and a weight of zero to noncontiguous cities (the weight matrix is denoted $W^{\text {Pcont }}$ ). The second scheme deflates the competing city's population by the smooth distance decay, with weights given by $\omega_{i j}=P_{j} / d_{i j}$ for $j \neq i$ (the weight matrix is $W^{P / d}$ ). As in the pure distance schemes, the latter weight matrices are row-normalized.

\subsection{Data and Socio-Economic Characteristics}

We use two cross-section samples, which cover 70 cities in the Boston metropolitan area (see Table 5 below for a list). The first sample is for 1980, the year before Proposition $2 \frac{1}{2}$ became effective. The second sample is for 1990, a year by which the effects of Proposition $2 \frac{1}{2}$ were well established. To compute the effective property-tax rate prevailing in each city in 1980, the city's nominal tax rate is multiplied by the ratio of total assessed property value to total market value. ${ }^{8}$ Since Massachusetts shifted to full-value assessment after Proposition $2 \frac{1}{2}$, the nominal tax rates for 1990 are the effective rates, so that they can be used directly. It is important to note that, given the coterminous arrangement of school districts and cities, the property-tax rates for both years cover education as well as municipal spending.

The socio-economic variables used in the regressions are per capita income, per capita state aid, the African-American proportion of the population, the proportion of the adult population with at least a college education, public sector earnings per capita, and the annual rate of population growth. ${ }^{9}$ Since the per capita property-tax base rises with income in our sample, we expect that high-income cities can satisfy their residents' high public-good demands 
with relatively low tax rates, conditional on the tax rates in other communities. ${ }^{10}$ Similarly, since a high level of state aid increases the resources available to a city, this should allow a reduction in its tax rate. The African-American population share is included in part because it measures poverty, but also because it may capture any differential public service needs of a minority population. ${ }^{11}$ Since the demand for school spending is likely to be high in cities with many college-educated residents, we expect relatively high tax rates in such cities, holding tax rates in other communities fixed.

A public-sector earnings variable is included to control for the cost of public good provision, with the expectation that cities with high labor costs will have high tax rates. Because of missing observations on public-sector employment made it impossible to compute a variable giving earnings per employee, we divide total public-sector wages and salaries by the city's population. The resulting variable partly captures the effect of high wages, but it will also be large when public employment per capita is large. While this raises the possibility of endogeneity, we retained this variable because of a desire to include a cost measure in the estimating equation. ${ }^{12}$

To capture growth effects, the city's annual rate of population growth is computed over the previous decade for the two sample years (over 1970-80 for the 1980 sample, and 1980-90 for the 1990 sample). Fast-growing cities tend to be relatively young, and although they face substantial demands for new infrastructure, they benefit from burgeoning tax bases and are free of many of the spending demands faced by older, established cities. If the latter effects dominate, then tax rates will tend to be lower in fast-growing cities. ${ }^{13}$ Because the growth rate is measured over the previous decade, the possibility of simultaneous determination of growth and the tax rate is lessened.

Recall from above that the intercept of the reaction function depends (along with the slope) on the distribution of the metropolitan population. This suggests that the city's own population can be included in the $Z$ matrix in (10) as one of the variables shifting the reactionfunction intercept. However, when population appears in the estimating equation along with the above variables, the regression diagnostics are unsatisfactory, with the residuals indicating nonnormal errors for three of the five weighting schemes. As a result, only the variables 
discussed above are included in the main specification presented in the next section. Additional results are given for an equation including population, using the two weighting schemes where the diagnostics are acceptable.

Table 1 presents means and standard deviations for the variables in the empirical model. In the estimation, all variables except for the population growth rate are expressed in natural-log form.

\section{Estimation Results for $\mathbf{1 9 8 0}$}

The model (10) is estimated using the five different weighting schemes discussed in Section 3.2. Table 2 reports the coefficient estimates and their corresponding asymptotic standard normal statistics ( $z$-values, in parenthesis). In addition, the Table shows the values of the various test statistics and their corresponding probability values ( $p$-values, in parenthesis).

The most important results in Table 2 are the estimates of $\phi$, the reaction-function slope parameter. To start, consider the results in the first five columns of the Table, which pertain to the specification without the population variable. Table 2 reveals that under this specification, the estimated slope coefficient is positive and significantly different from zero under four of the five weighting schemes. While $\phi$ is not significant in the specification with weight matrix $W^{P}$, evidence of strategic interaction emerges under schemes where the weights reflect distance between competing communities or a combination of distance and population. ${ }^{14}$ These results suggest that strategic property-tax competition occurred in the Boston metropolitan area in 1980, and that the interaction generated an upward-sloping reaction function. This means that community $i$ 's best response to an increase in the property-tax rates of competing communities was to increase its own tax rate. In game-theoretic language, our findings indicate that the tax rates of competing communities are "strategic complements." In their study of Belgian municipalities, Heyndels and Vuchulen (1998) reached the same conclusion.

The middle of Table 2 contains the results for the normality and heteroscedasticity tests. To check the normality assumption on the error term $\epsilon$ in (10), we report the Kiefer-Salmon test, whose values indicate that the hypothesis of normal errors cannot be rejected under any of the weighting schemes. We also report the Breusch-Pagan test for heteroskedasticity, which has 
good performance under the assumption of normal errors. The value of this statistic indicates that the hypothesis of constant error variance cannot be rejected for any of the estimated models at the chosen confidence level.

As noted above, the slope parameter $\phi$ may appear to be statistically different from zero when $\phi=0$ holds in the true model but the errors are spatially dependent. To avoid attributing a spurious significance to the slope parameter, we first perform a robust Lagrange multiplier test of the hypothesis $\phi=0$, which is valid in the presence of uncorrected spatial error dependence, as explained above. The test results are consistent with the findings reported above, with the slope parameter $\phi$ significantly different from zero at the 5 percent level under all specifications.

To determine whether spatial error dependence has been improperly ignored, consider first the conditional test for spatial dependence, which is computed using the estimates of the spatial lag model (recall this test may be misleading). This test, which is shown along with the other tests of error specification in Table 2, shows that we cannot reject the null hypothesis of independent errors in each case. The robust test, which is based on OLS results and does not suffer from the potential bias of the conditional test, generates similar results. Finally, we can reject the common factor hypothesis for all four of the distance-based weighting schemes, indicating that the spatial error model is not appropriate for any of these specifications.

Taken together, these tests suggest that our finding of a nonzero $\phi$ is not a spurious result due to uncorrected spatial error dependence. The tests thus give additional support to our conclusion that strategic property-tax competition occurred among local governments in the Boston metropolitan area prior to the imposition of Proposition $2 \frac{1}{2}$.

Turning to the effects of the socio-economic characteristics, observe that all of the coefficients are statistically different from zero, and that their estimated values are similar across the different weighting schemes. The negative coefficient on per capita income indicates that the higher per capita tax bases in well-off cities allow public spending demands to be satisfied with lower tax rates. The positive effect of the education variable appears to reflect the strong demand for school spending in highly-educated cities, which leads to higher tax rates. The negative coefficient on population growth indicates that the beneficial effect of growth on the tax base outstrips its effect on spending needs, permitting lower tax rates. The positive 
public-sector earnings coefficient suggests that tax rates are high in cities where public-sector wages are high, a response to higher cost of public-good provision. Recall, however, that a large value for this variable may simply indicate high public employment per capita in the city, making the cost interpretation incorrect.

Cities where the African-American population share is high also have high tax rates. Recognizing that African-American incomes are low on average, it is likely that this finding simply reconfirms the inverse relationship between tax rates and income found above. Alternatively, the positive coefficient may reflect differential public spending needs associated with a large minority population. ${ }^{15}$

State aid per capita, the last socio-economic variable, has a significantly positive coefficient. Since intuition suggests that higher state aid should allow a reduction in taxes, this result is unexpected. The apparent explanation is that state aid serves as a proxy for other city characteristics. For example, state-aid formulas typically generate an inverse correlation between aid and the per capita tax base, which is in turn increasing in income. Therefore, high state aid may signal low income, which is in turn associated with high tax rates given the above results. 16

Consider finally the last two columns of Table 2, which report results for the specification that includes the city's population along with the above variables. As noted earlier, the diagnostics for this equation were acceptable only under two of the weighting schemes, both of which involve contiguity. Under both contiguity schemes, the $\phi$ estimate is positive and significant, as before. ${ }^{17}$ In addition, the coefficients of income, state aid, and the black population proportion retain their former signs and significance. While the variables measuring education, population growth, and public sector earnings no longer have significant coefficients, the coefficient of the new variable, population, is positive and strongly significant under the simple contiguity scheme. Population has no effect on the tax rate, however, under the population-weighted contiguity scheme. ${ }^{18}$ Since Table 2 shows that the various tests yield the same favorable results as in the previous cases, the modified specification supports the earlier conclusion that strategic interaction occurred among Boston-area cities in $1980 .{ }^{19}$ 


\section{Estimation Results for $\mathbf{1 9 9 0}$}

This section reports estimation results for the period after the passage of Proposition $2 \frac{1}{2}$, focusing on the year 1990. Proposition $2 \frac{1}{2}$, which was designed to limit the property-tax burden in Massachusetts, initially restricted the total property-tax revenue (the tax "levy") in each city to be less than 2.5 percent of the total market value of property. Any city whose tax levy initially exceeded this limit was required to reduce its levy by 15 percent per year until the restriction was met. According to Bradbury (1988), roughly half of Massachusetts municipalities were required to make this adjustment, and all but two had reduced their levies by the required amount by 1984 . Thereafter, the yearly increase in the tax levy was restricted. The absolute increase could not exceed 2.5 percent of the previous year's levy plus any gains from new construction. ${ }^{20}$ Adding this increment to the previous levy generates a ceiling known as the "levy limit," which moved upward over time.

Given the boom in Massachusetts real estate markets in the 1980s, which pushed property values up by more than 2.5 percent per year, the restriction on tax-levy growth guaranteed a decline in tax rates over time (driving them below 2.5 percent on average by 1990 , as seen in Table 1). This decline occurred eventually even in cities where initial cuts in the levy were not required, as the rate-of-increase restriction on the levy became binding. ${ }^{21}$ In addition to

these effects on overall tax rates, Proposition $2 \frac{1}{2}$ also led to replacement of the old uniform tax system, where all property was taxed at the same nominal rate, with a classified tax system, where business and residential rates could differ.

If all cities were constrained by Proposition $2 \frac{1}{2}$, each tax rate would simply equal the levy limit divided by total property value. With taxes thus constrained, the choice problem described in Section 2, which presumes interior solutions, would no longer be relevant. As a result, we might expect that evidence of strategic behavior, present in 1980, would have disappeared by 1990. Given that almost 300 of Massachusetts' 351 municipalities were taxing at their levy limits in 1990 (see Bradbury (1991)), it would appear that little scope for strategic behavior existed in that year. ${ }^{22}$

To test this hypothesis, we repeat the estimation of Section 4, with several changes. First, the public sector earnings variable, which is not available in 1990 for cities with populations 
under 25,000, is dropped. In addition, a variable equal to the city's 1989 tax levy, which determines 1990's levy limit, is added to the equation (this variable is expressed in per capita terms). With most cities constrained by the levy limit, the coefficient on this variable should be positive.

The first specification uses the average property-tax rate for each city, which is computed by taking a weighted average of the residential and business rates, with the weights given by the relevant shares of total property value. This calculation obscures the differential taxation of residential and business property, but it provides results comparable to those in Table 2. Table 3 shows the estimated coefficients under the previous weighting schemes for this modified specification (population is not included). The striking feature of the Table is that none of the $\phi$ estimates is significantly different from zero, indicating the absence of strategic interaction. In addition, the coefficient on the lagged per capita levy is positive and strongly significant, showing the effect of the tax-revenue constraint. Consistent with the presence of such a constraint, the impact of city characteristics on property-tax choices is muted. Only the coefficients on per capita income and state aid retain their previous signficance.

If the estimation is repeated using the residential property-tax rate instead of the average rate, the results are similar, with the $\phi$ estimates insignificant. When the business tax rate is used, however, evidence of strategic interaction reemerges. Table 4 shows that the $\phi$ estimates are positive and significant in this case under both of the contiguity weighting schemes, and that the lagged-levy coefficient is positive and strongly significant in all cases. In addition, per capita income and the black population proportion retain their former effects. ${ }^{23}$ The same conclusion holds in the specification that includes population, which is shown in the third and fourth columns of Table 4. The coefficients on income and the lagged levy remain significant in these equations, but population is the only other variable with a nonzero effect.

These results suggest that even though the phenomenon is more elusive than before, strategic interaction apparently still occurs in the post-Proposition $2 \frac{1}{2}$ environment in the choice of business property taxes. As Table 4 shows, however, the interaction appears to be spatially limited, occurring only among contiguous cities. These findings are plausible given that Proposition $2 \frac{1}{2}$ limited the tax levy without placing strong restrictions on the mix of revenue from 
business and residential sources. ${ }^{24}$ As a result, communities had freedom to adjust their business and residential tax rates separately, as long as the levy limit was not violated. The results show that, in choosing its business tax rate, a city responds to the level of business taxes in nearby communities.

\section{A Simulation Exercise}

As explained above, the tax rate for any given city in a Nash equilibrium depends on the characteristics of all the cities in the metropolitan area. This fact, which is a key implication of strategic interaction, can be illustrated via a simulation exercise based on the 1980 results. In particular, suppose that per capita income rises in a given city. Since the coefficient of the income variable is negative in Table 2 , it follows that the reaction function for that city shifts down, as shown in Figure 1 for the two-city case. As can be seen, the shift in city 1's reaction function leads to a decline in the tax rates in both cities. This effect also emerges in a model with many cities, and numerical magnitudes can be illustrated using the model's estimated coefficients.

To see this, suppose per capita income for the city of Cambridge increases by 25 percent. ${ }^{25}$ In addition, suppose that interactions are described by the weight matrix $W^{d}$, which uses the smooth distance decay without adjustment for population. Referring to (11), the vector of tax-rate changes for all the sample cities is given by

$$
\left(I-\hat{\phi} W^{d}\right)^{-1}\left(Z_{1}-Z_{0}\right) \hat{\theta}=\left(I-\hat{\phi} W^{d}\right)^{-1}\left(I N C_{1}-I N C_{0}\right) \hat{\theta}_{I N C}
$$

where $Z_{0}$ and $Z_{1}$ are the $Z$ matrices before and after the income change, $I N C_{0}$ and $I N C_{1}$ are the column vectors of incomes before and after the change, and $\hat{\theta}_{I N C}$ is the estimated income coefficient. Under the given scenario, all elements of the vector $I N C_{1}-I N C_{0}$ are zero except for the Cambridge element.

The results of the calculation based on (13) are shown in Table 5. Naturally, the largest tax-rate decline occurs in Cambridge, whose rate falls by 1.3 percentage points. Taxes also decline appreciably in the neighboring cities of Boston, Chelsea, Somerville, and Medford. Tax rates in other cities, however, decline by smaller amounts. These numbers show that, with 
strategic interaction, a change in the characteristics of a single city generates a cascade of taxrate changes throughout the metropolitan area. This interdependence is an important feature of models of strategic tax competition.

\section{Conclusion}

This paper has provided empirical evidence on property-tax competition among local governments. Reaction functions have been estimated using the techniques of spatial econometrics, with a nonzero slope coefficient providing evidence of strategic interaction in the choice of tax rates. The 1980 results yield slope estimates that are positive and significantly different from zero, suggesting that strategic tax competition occurred in the Boston metropolitan area in the pre-tax-limitation era. Interestingly, the evidence shows that tax competition persisted, although in a less pervasive manner, after Proposition $2 \frac{1}{2}$ despite the restrictions imposed by this tax limitation measure.

Although the strategic Tiebout/tax-competition model sketched in Section 2 was used to motivate the empirical work, it is important to ask whether other models would generate a similar empirical framework. Models of "yardstick" competition, as exemplified by Besley and Case (1995), in fact may be observationally equivalent to the current model. In a localgovernment version of the Besley-Case framework, consumers would look at tax rates in other communities to help judge whether their local government is wasting tax revenue and deserves to be voted out of office. Since self-interested government officials choose tax rates knowing that consumers make such comparisons, strategic interaction among communities arises, as in a tax-competition model.

While our results are consistent with the tax-competition model, the results cannot prove that the model is correct as a description of how property-tax rates are chosen. However, the voluminous tax-competition literature shows that tax-base flight is widely thought to be a concern when jurisdictions set tax rates, and thus an important source of strategic interaction among them. Our use of the tax-competition model in motivating the empirical work reflects this theoretical orientation. Other models (including the yardstick framework) may have relevance, however, and further work is needed to decide which model is most appropriate. 


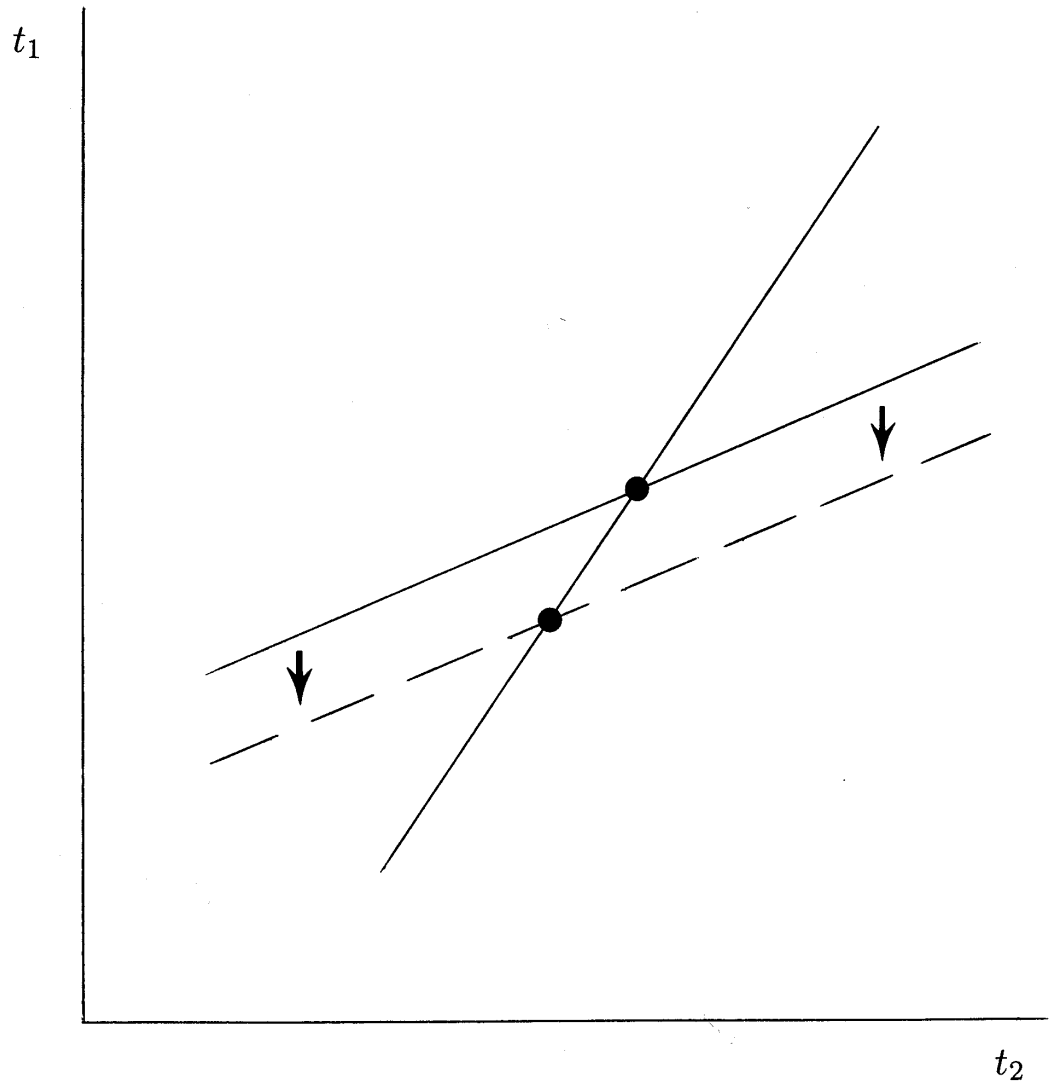

Figure 1: Reaction functions 
Table 1.

Descriptive Statistics

\begin{tabular}{lcccc} 
Variables & \multicolumn{2}{c}{1980} & \multicolumn{2}{c}{1990} \\
& Mean & S.Dev. & Mean & S.Dev. \\
\cline { 2 - 5 } & & & & \\
Effective Total Prop. Tax Rate & 4.44 & 1.50 & 1.15 & 0.15 \\
Effective Business Prop. Tax Rate & - & - & 1.49 & 0.43 \\
Per Capita Income & 8793 & 2162 & 21278 & 6231 \\
Per Capita State Aid & 167.5 & 52.1 & 308.1 & 146.2 \\
Popu. Prop. with 16 + Yr. Educ. & 0.162 & 0.09 & 0.239 & 0.107 \\
Annual Rate of Popu. Growth & 0.008 & 1.09 & 0.078 & 0.52 \\
Popu. Prop. Afro-American & 0.015 & 0.03 & 0.024 & 0.038 \\
Per Capita Pub. Sec. Earnings & 546.72 & 130.0 & - & - \\
Lagged Per Capita Levy ${ }^{1}$ & - & - & 851.4 & 249.8 \\
Population & 38682 & 67109 & 38843 & 68313 \\
\hline 1 Per capita levy corresponds to the year 1989 & & & &
\end{tabular}

${ }^{1}$ Per capita levy corresponds to the year 1989 
Table 2.

Estimates For 1980

Dependent Variable:

Ln Eff. Prop. Tax Rt., 1980 (t)

Coefficient Estimates ${ }^{1}$

\section{Explanatory Variables:}

Wt

Constant

Ln Per Capita Income

Ln Per Capita State Aid

Ln Popu. Prop. with 16+ Yr. Educ.

Annual Rate Popu. Growth

Ln Popu. Prop. Afro-American

Ln Per Cap. Pub. Sec. Earn.

Ln Population

\section{Tests of Error Specific. ${ }^{2}$}

LM Breusch-Pagan Heterosked.

$\begin{array}{ccccccc}1.69 & 2.04 & 2.34 & 2.03 & 2.28 & 4.46 & 4.83 \\ (0.95) & (0.92) & (0.89) & (0.92) & (0.89) & (0.73) & (0.68) \\ 0.88 & 0.31 & 1.06 & 0.13 & 0.98 & 1.58 & 3.79 \\ (0.64) & (0.86) & (0.59) & (0.93) & (0.61) & (0.45) & (0.15) \\ 0.37 & 0.45 & 1.59 & 0.00 & 1.28 & 3.26 & 0.86 \\ (0.55) & (0.50) & (0.21) & (0.99) & (0.26) & (0.07) & (0.35)\end{array}$

\section{Robust Tests of Spat. Dep.}

LM Test Spat. Lag Depen.

$\begin{array}{ccccccc}9.06 & 9.06 & 5.30 & 5.42 & 5.18 & 12.41 & 5.98 \\ (0.00) & (0.00) & (0.02) & (0.02) & (0.02) & (0.00) & (0.01) \\ 1.32 & 3.77 & 3.64 & 0.11 & 1.47 & 6.15 & 2.34 \\ (0.25) & (0.05) & (0.06) & (0.74) & (0.23) & (0.01) & (0.13)\end{array}$

\section{Common Factor Test}

$\begin{array}{lllllllc}\text { LR Test on Common Factor Hyp. } & 18.44 & 20.63 & 10.25 & 12.03 & 18.49 & 24.20 & 14.5 \\ & (0.00) & (0.00) & (0.11) & (0.06) & (0.00) & (0.00) & (0.04)\end{array}$

\footnotetext{
1 Asymptotic standard normal statistics are given in parenthesis.

${ }^{2}$ Probability values are given in parenthesis.
} 
Table 3.

Estimates For 1990

Dependent Variable:

Ln Eff. Total Prop. Tax Rt., 1990 (t)

Coefficient Estimates ${ }^{1}$

\section{Explanatory Variables:}

\begin{tabular}{ccccc}
\hline$W^{\text {cont }}$ & $W^{d}$ & $W^{P}$ & $W^{\text {Pcont }}$ & $W^{P / d}$ \\
\hline 0.08 & -0.60 & 0.42 & 0.04 & 0.20 \\
$(0.59)$ & $(-0.92)$ & $(1.27)$ & $(0.35)$ & $(0.57)$ \\
0.31 & 0.37 & 0.33 & 0.32 & 0.29 \\
$(0.20)$ & $(0.24)$ & $(0.22)$ & $(0.21)$ & $(0.19)$ \\
-0.38 & -0.36 & -0.38 & -0.38 & -0.38 \\
$(-2.89)$ & $(-2.76)$ & $(-2.91)$ & $(-2.86)$ & $(-2.85)$ \\
0.12 & 0.12 & 0.12 & 0.12 & 0.12 \\
$(2.14)$ & $(2.18)$ & $(2.15)$ & $(2.12)$ & $(2.11)$ \\
0.03 & 0.02 & 0.03 & 0.02 & 0.02 \\
$(0.62)$ & $(0.56)$ & $(0.65)$ & $(0.58)$ & $(0.58)$ \\
0.02 & 0.02 & 0.02 & 0.02 & 0.02 \\
$(0.92)$ & $(0.72)$ & $(0.78)$ & $(0.86)$ & $(0.82)$ \\
0.02 & 0.02 & 0.02 & 0.02 & 0.02 \\
$(1.47)$ & $(1.65)$ & $(1.52)$ & $(1.51)$ & $(1.52)$ \\
0.44 & 0.42 & 0.43 & 0.44 & 0.44 \\
$(6.32)$ & $(5.91)$ & $(6.22)$ & $(6.26)$ & $(6.24)$
\end{tabular}

Tests of Error Specification ${ }^{2}$

LM Breusch-Pagan Heterosked.

3.43

3.54

2.94

3.32

$(0.82)$

$(0.75)$

$(0.74)$

$(0.82)$

$(0.77)$

Kiefer-Salmon Normality Test

$\begin{array}{lllll}0.80 & 1.17 & 0.69 & 0.81 & 0.75\end{array}$

$\begin{array}{lllll}(0.67) & (0.56) & (0.71) & (0.67) & (0.69)\end{array}$

LM Test of Spat. Error Depen.

$\begin{array}{ccccc}0.66 & 0.06 & 0.11 & 0.08 & 0.00\end{array}$

$\begin{array}{lllll}(0.42) & (0.81) & (0.75) & (0.77) & (0.99)\end{array}$

\section{Robust Tests of Spat. Dep.}

LM Test of Spat. Lag Depen.

$\begin{array}{ccccc}1.27 & 0.42 & 3.74 & 0.28 & 0.27 \\ (0.26) & (0.52) & (0.05) & (0.60) & (0.60) \\ 1.03 & 0.19 & 2.76 & 0.15 & 0.17 \\ (0.31) & (0.66) & (0.10) & (0.70) & (0.68)\end{array}$

\section{Common Factor Test}

LR Test on Common Factor Hyp.

$\begin{array}{ccccc}22.57 & 15.42 & 4.31 & 18.42 & 12.81 \\ (0.001) & (0.02) & (0.63) & (0.005) & (0.05)\end{array}$

\footnotetext{
${ }^{1}$ Asymptotic standard normal statistics are given in parenthesis.

2 Probability values are given in parenthesis.
} 
Table 4.

\section{Estimates For 1990}

Dependent Variable:

Ln Eff. Business Prop. Tax Rt., 1990 (t)

\section{Explanatory Variables:}

$\mathrm{Wt}$

Constant

Ln Per Capita Income

Ln Per Capita State Aid

Ln Popu. Prop. with 16+ Yr. Educ.

Annual Rate of Popu. Growth

Ln Popu. Prop. Afro-American

Ln Lagged Per Capita Levy

Ln Population

\section{Tests of Error Specification ${ }^{2}$}

LM Breusch-Pagan Heterosked.

Kiefer-Salmon Normality Test

LM Test of Spat. Error Depen.

\section{Robust Tests of Spat. Dep.}

LM Test of Spat. Lag Depen.

$\begin{array}{cccc}6.97 & 3.00 & 9.33 & 4.16 \\ (0.00) & (0.08) & (0.00) & (0.04) \\ 1.27 & 0.18 & 3.28 & 0.95 \\ (0.26) & (0.67) & (0.07) & (0.33)\end{array}$

\section{Common Factor Test}

LR Test on Common Factor Hyp.
Coefficient Estimates ${ }^{1}$

\begin{tabular}{cccc}
\hline$W^{\text {cont }}$ & $W^{\text {Pcont }}$ & $W^{\text {cont }}$ & $W^{\text {Pcont }}$ \\
\hline 0.37 & 0.26 & 0.34 & 0.23 \\
$(3.53)$ & $(2.40)$ & $(3.38)$ & $(2.29)$ \\
1.68 & 2.28 & -0.27 & 0.10 \\
$(0.55)$ & $(0.71)$ & $(-0.08)$ & $(0.03)$ \\
-0.76 & -0.79 & -0.63 & -0.64 \\
$(-2.86)$ & $(-2.85)$ & $(-2.33)$ & $(-2.30)$ \\
0.17 & 0.15 & 0.15 & 0.12 \\
$(1.54)$ & $(1.24)$ & $(1.35)$ & $(1.06)$ \\
0.02 & 0.01 & -0.02 & -0.03 \\
$(0.21)$ & $(0.11)$ & $(-0.23)$ & $(-0.33)$ \\
-0.04 & -0.05 & -0.01 & -0.03 \\
$(-0.76)$ & $(-1.14)$ & $(-0.26)$ & $(-0.58)$ \\
0.07 & 0.08 & 0.04 & 0.05 \\
$(2.51)$ & $(2.62)$ & $(1.36)$ & $(1.39)$ \\
0.76 & 0.74 & 0.73 & 0.71 \\
$(5.43)$ & $(5.09)$ & $(5.31)$ & $(4.98)$ \\
- & - & 0.09 & 0.10 \\
& & $(1.89)$ & $(1.99)$
\end{tabular}

$\begin{array}{cccc}5.50 & 5.57 & 7.30 & 7.82 \\ (0.48) & (0.47) & (0.40) & (0.35) \\ 2.73 & 3.67 & 1.67 & 2.37 \\ (0.25) & (0.16) & (0.43) & (0.31) \\ 0.01 & 0.01 & 0.87 & 0.33 \\ (0.91) & (0.92) & (0.35) & (0.56)\end{array}$

LM Test of Spat. Error Depen.

\footnotetext{
1 Asymptotic standard normal statistics are given in parenthesis.

2 Probability values are given in parenthesis.
} 
Table 5.

Comparative-Static Exercise For 1980: Predicted Taxes After 25\% Increase In Cambridge's Per Capita Income ${ }^{1}$

\begin{tabular}{llll} 
& \multicolumn{3}{c}{ Predicted Tax Rate } \\
\cline { 2 - 4 } Cities & Before & After & Difference \\
\cline { 2 - 4 } & & & \\
ABINGTON & 3.7418 & 3.7152 & -0.0266 \\
ACTON & 2.6728 & 2.6511 & -0.0217 \\
ARLINGTON & 4.0003 & 3.9573 & -0.0430 \\
BEDFORD & 4.6443 & 4.6051 & -0.0392 \\
BELLINGHAM & 4.6297 & 4.5944 & -0.0354 \\
BELMONT & 3.6196 & 3.5783 & -0.0413 \\
BEVERLY & 3.7928 & 3.7637 & -0.0292 \\
BOSTON & 9.9856 & 9.8587 & -0.1269 \\
BRAINTREE & 3.5970 & 3.5697 & -0.0273 \\
BROCKTON & 5.9512 & 5.9079 & -0.0433 \\
BROOKLINE & 4.0071 & 3.9539 & -0.0532 \\
BURLINGTON & 4.2635 & 4.2279 & -0.0356 \\
CAMBRIDGE & 7.3624 & 6.0481 & -1.3143 \\
CANTON & 3.9013 & 3.8713 & -0.0300 \\
CHELSEA & 7.3981 & 7.3278 & -0.0703 \\
CONCORD & 3.5109 & 3.4820 & -0.0289 \\
DANVERS & 4.3756 & 4.3420 & -0.0336 \\
DEDHAM & 3.4943 & 3.4649 & -0.0294 \\
DUXBURY & 3.1729 & 3.1492 & -0.0237 \\
EVERETT & 4.6125 & 4.5646 & -0.0479 \\
FOXBOROUGH & 4.3404 & 4.3084 & -0.0319 \\
FRAMINGHAM & 4.2761 & 4.2422 & -0.0339 \\
FRANKLIN & 4.6644 & 4.6291 & -0.0352 \\
HANOVER & 4.4345 & 4.4026 & -0.0319 \\
HINGHAM & 3.7827 & 3.7537 & -0.0290 \\
HOLBROOK & 4.8082 & 4.7732 & -0.0351 \\
LEXINGTON & 4.0488 & 4.0117 & -0.0371 \\
LYNN & 6.6083 & 6.5552 & -0.0531 \\
LYNNFIELD & 2.8188 & 2.7966 & -0.0222 \\
MALDEN & 5.0460 & 4.9973 & -0.0487 \\
MARBLEHEAD & 3.1871 & 3.1631 & -0.0240 \\
MARSHFIELD & 3.4407 & 3.4153 & -0.0254 \\
MEDFIELD & 3.6871 & 3.6589 & -0.0282 \\
MEDFORD & 5.3279 & 5.2654 & -0.0625 \\
MELROSE & 4.2627 & 4.2250 & -0.0376 \\
MILTON & 3.6110 & 3.5804 & -0.0306 \\
NATICK & 4.4825 & 4.4466 & -0.0358 \\
NEEDHAM & 3.6113 & 3.5804 & -0.0309 \\
NEWTON & 4.2976 & 4.2553 & -0.0423 \\
& & &
\end{tabular}




\section{Table 5. - Continued}

\begin{tabular}{|c|c|c|c|}
\hline \multirow[b]{2}{*}{ Cities } & \multicolumn{3}{|c|}{ Predicted Tax Rate } \\
\hline & Before & After & Difference \\
\hline NORTH READING & 3.9841 & 3.9525 & -0.0316 \\
\hline NORWOOD & 4.0013 & 3.9709 & -0.0304 \\
\hline PEABODY & 4.3537 & 4.3200 & -0.0337 \\
\hline PEMBROKE & 3.4866 & 3.4614 & -0.0252 \\
\hline QUINCY & 4.6568 & 4.6182 & -0.0386 \\
\hline RANDOLPH & 4.6835 & 4.6483 & -0.0352 \\
\hline READING & 3.7395 & 3.7093 & -0.0302 \\
\hline REVERE & 4.3699 & 4.3305 & -0.0395 \\
\hline ROCKLAND & 5.1645 & 5.1277 & -0.0368 \\
\hline SALEM & 4.6840 & 4.6489 & -0.0351 \\
\hline SAUGUS & 3.7390 & 3.7074 & -0.0316 \\
\hline SCITUATE & 4.0579 & 4.0268 & -0.0310 \\
\hline SHARON & 4.2071 & 4.1764 & -0.0307 \\
\hline SOMERVILLE & 6.1793 & 6.0606 & -0.1187 \\
\hline STONEHAM & 3.5737 & 3.5430 & -0.0307 \\
\hline STOUGHTON & 4.0707 & 4.0408 & -0.0299 \\
\hline SUDBURY & 3.3120 & 3.2854 & -0.0266 \\
\hline SWAMPSCOTT & 3.5597 & 3.5315 & -0.0282 \\
\hline WAKEFIELD & 3.8877 & 3.8561 & -0.0316 \\
\hline WALPOLE & 4.2516 & 4.2199 & -0.0317 \\
\hline WALTHAM & 4.2648 & 4.2236 & -0.0412 \\
\hline WATERTOWN & 4.3300 & 4.2735 & -0.0565 \\
\hline WAYLAND & 3.9522 & 3.9201 & -0.0322 \\
\hline WELLESLEY & 3.7531 & 3.7214 & -0.0316 \\
\hline WESTON & 2.7757 & 2.7518 & -0.0240 \\
\hline WESTWOOD & 3.4604 & 3.4332 & -0.0272 \\
\hline WEYMOUTH & 4.0783 & 4.0468 & -0.0315 \\
\hline WILMINGTON & 4.1139 & 4.0807 & -0.0332 \\
\hline WINCHESTER & 3.9546 & 3.9170 & -0.0376 \\
\hline WINTHROP & 4.2850 & 4.2448 & -0.0401 \\
\hline WOBURN & 4.1140 & 4.0784 & -0.0357 \\
\hline
\end{tabular}

${ }^{1}$ The weigth matrix $W^{d}$ is used in this exercise. 


\section{References}

Anselin, L., 1988, Spatial econometrics: Methods and models (Kluwer Academic Publishers, Dordrecht).

Anselin, L., 1992, SpaceStat: A program for the analysis of spatial data, Regional Research Institute, West Virginia.

Anselin, L. And A.K. BerA, 1996, Spatial dependence in linear regression models with an introduction to spatial econometrics, Discussion Paper, University of Illinois.

Anselin, L., A.K. Bera, R. Florax, and M.J. Yoon, 1996, Simple diagnostic tests for spatial dependence, Regional Science and Urban Economics 26, 77-104.

BECK, J.H., 1983, Tax competition, uniform assessment, and the benefit principle, Journal of Urban Economics 13, 127-146.

Besley, T. And A. CAse, 1996, Incumbent behavior: Vote-seeking, tax-setting, and yardstick competition, American Economic Review 85, 25-45.

Boskin, M.J., 1973, Local government tax and product competition and the optimal provision of public goods, Journal of Political Economy 81, 203-210.

Bradbury, K.L., 1988, Shifting property tax burdens in Massachusetts, New England Economic Review, September/October, 36-48.

Bradbury, K.L., 1991, Can local governments give citizens what they want? Referendum outcomes in Massachusetts, New England Economic Review, May/June, 3-22.

BraID, R., 1996, Symmetric tax competition with multiple jurisdictions in each metropolitan area, American Economic Review 86, 1279-1290.

Brueckner, J.K., 1998, Testing for strategic interaction among local governments: The case of growth controls, Journal of Urban Economics 44, 438-467.

Brueckner, J.K., 1999, A Tiebout/tax-competition model, forthcoming, Journal of Public Economics.

Bucovetsky, S., 1991, Asymmetric tax competition, Journal of Urban Economics 30, 167181.

Bucovetsky, S., 1995, Rent seeking and tax competition, Journal of Public Economics 58, 
$337-363$.

Bucovetsky, S. And J.D. Wilson, 1991, Tax competition with two instruments, Regional Science and Urban Economics 21, 333-350.

Burbidge, J.B. And G.M. Myers, 1994, Population mobility and tax competition, Regional Science and Urban Economics 24, 441-459.

Case, A.C., H.S. Rosen And J.R. Hines, 1993, Budget spillovers and fiscal policy interdependence: Evidence from the states, Journal of Public Economics 52, 285-307.

Commonwealth of Massachsetts, Department of Revenue, 1980, 1980 Equalized Valuations of Massachusetts Cities and Towns (Bureau of Local Assessment, Boston).

DePater, J.A. And G.M. Myers, 1994, Strategic capital tax competition: A pecuniary externality and a corrective device, Journal of Urban Economics 36, 66-78.

Epple, D. And T. Romer, 1991, Mobility and redistribution, Journal of Political Economy 89, $1197-1217$.

Figlio, D.N., V.W. Kolpin And W. Reid, 1997, Do states play welfare games? Journal of Urban Economics, forthcoming.

Henderson, J.V., 1994, Community choice of revenue instruments, Regional Science and Urban Economics 24, 159-183.

Henderson, J.V., 1995, Will homeowners impose property taxes? Regional Science and Urban Economics 25, 153-181.

Heyndels, B. And J. Vuchelen, 1998, Tax mimicking among Belgian municipalities, $N a-$ tional Tax Journal 51, 89-101.

Hoyt, W.H., 1991a, Competitive jurisdictions, congestion, and the Henry George theorem: When should property be taxed instead of land? Regional Science and Urban Economics 21, 351-370.

Hoyt, W.H., 1991b, Property taxation, Nash equilibrium, and market power, Journal of Urban Economics 30, 123-131.

Hоyт, W.H., 1992, Market power of large cities and policy differences in metropolitan areas, Regional Science and Urban Economics 22, 539-558.

Hoyt, W.H., 1993, Tax competition, Nash equilibria, and residential mobility, Journal of Urban Economics 34, 358-379. 
Kolstad, C.D. And F.A. Wolak, 1983, Competition in interregional taxation: the case of western coal, Journal of Political Economy 91, 443-460.

Krelove, R., 1993, The persistence and inefficiency of property tax finance of local expenditures, Journal of Public Economics 51, 415-435.

LEE, K., 1997, Tax competition with imperfectly mobile capital, Journal of Urban Economics, forthcoming.

Lenon, M., S.K. Chattopadhyay and D.R. Heffley, 1996, Zoning and fiscal interdependencies, Journal of Real Estate Finance and Economics 12, 221-232.

Massachusetts Taxpayers Foundation, 1980 and 1981, Municipal Financial Data (Massachusetts Taxpayers Foundation, Boston).

Mintz, J. And H. Tulkens, 1986, Commodity tax competition between member states of a federation: Equilibrium and efficiency, Journal of Public Economics 29, 133-172.

OAtes, W.E., 1972, Fiscal Federalism (Harcourt Brace, New York).

Oates, W.E. And R.M. Schwab, 1988, Economic competition among jurisdictions: Efficiency enhancing or distortion reducing? Journal of Public Economics 35, 333-354.

PAuly, M.V., 1970, Optimality, 'public' goods, and local governments: A general theoretical analysis, Journal of Political Economy 78, 572-585.

SAAVEDRA, L.A., 1998, A model of welfare competition with evidence from AFDC, Journal of Urban Economics, forthcoming.

Shroder, M., 1996, Games the states don't play: Welfare benefits and the theory of fiscal federalism, Review of Economics and Statistics 77, 183-191.

Smith, M.W., 1997, State welfare benefits: The political economy of spatial spillovers, unpublished paper, Yale University.

Tiebout, C.M., 1956, A pure theory of local expenditures, Journal of Political Economy 64, 416-424.

Wildasin, D.E., 1988a, Nash equilibria in models of fiscal competition, Journal of Public Economics 35, 241-249.

Wildasin, D.E., 1988b, Interjurisdictional capital mobility: Fiscal externality and a corrective subsidy, Journal of Urban Economics 25, 193-212. 
Wildasin, D.E., 1991, Some rudimentary 'duopolity' theory, Regional Science and Urban Economics 21, 393-421.

Williams, A., 1966, The optimal provision of public goods in a system of local governments, Journal of Political Economy 74, 18-33.

Wilson, J.D., 1986, A theory of interregional tax competition, Journal of Urban Economics 19, 296-315.

WiLson, J.D., 1991, Tax competition with interregional differences in factor endowments, Regional Science and Urban Economics 21, 423-451.

WiLson, J.D., 1995, Mobile labor, multiple tax instruments, and tax competition, Journal of Urban Economics 38, 333-356.

WiLson, J.D., 1997, Property taxation, congestion, and local public goods, Journal of Public Economics 64, 207-217.

WiLson, J.D., 1999, Theories of tax competition, National Tax Journal 52, 269-304.

Zodrow, G.R. And P. Mieszkowski, 1986, Pigou, Tiebout, property taxation, and the underprovision of local public goods, Journal of Urban Economics 19, 356-370. 


\section{Footnotes}

*We thank Dennis Epple, several referees, and seminar participants at several universities for helpful comments. Any errors or shortcomings in the paper, however, are our responsibility.

${ }^{1}$ Extensions of the competitive model are found in Braid (1996), Bucovetsky and Wilson (1991), Hoyt (1991a), Oates and Schwab (1988), Wildasin (1988b), and Wilson (1995). Extensions of the strategic model are found in Bucovetsky (1995), Burbidge and Myers (1994), DePater and Myers (1994), Henderson (1994, 1995), Hoyt (1991b, 1992, 1993), Krelove (1993), Lee (1997), Wildasin (1991), and Wilson (1991, 1997). A precursor to the entire literature is the study of Kolstad and Wolak (1983).

${ }^{2}$ Lenon, Chattopadhyay and Heffley (1996) estimate a model of local zoning decisions that is meant to capture interdependence among jurisidictions. However, their empirical procedures fail to account for the endogeneity of the choices of competing communities.

${ }^{3}$ Brueckner (1999) analyzes a Tiebout/tax-competition model assuming competitive, rather than strategic, behavior.

${ }^{4}$ Different conclusions emerge in the asymmetric case. Since the low-demand community ends up as a net importer of capital (see below), it benefits from the lower $\rho$ caused by an increase in its tax rate. This tendency may lead the community's equilibrium tax rate to be inefficiently high. The high-demand community, however, continues to set its tax rate inefficiently low. See Bucovetsky (1991) and Wilson (1991) for further discussion.

${ }^{5}$ The estimation is handled by the software package SpaceStat (version 1.80), written by Anselin (1992). By contrast, Heyndels and Vuchelen (1998) use instrumental-variables estimation.

${ }^{6}$ To see how the test is carried out, suppose the true model is the spatial error model, which consists of (12) and $t=Z \theta+\epsilon$. Then, after solving for $\epsilon$, substituting its value in the previous equation, and some manipulations, we obtain the equivalent model $t=\lambda W t+$ $Z \theta-\lambda W Z \theta+\mu$, known as the spatial Durbin model. This equation can be rewritten as $t=\lambda W t+Z \theta+W Z \delta+\mu$, and if the spatial error model is correct, the restriction $\delta=-\lambda \theta$ (known as the common factor hypothesis) must be satisfied. This restriction can be tested to indicate whether the spatial error model is appropriate.

${ }^{7}$ Distances are computed using the latitude and longitude of each city. 
${ }^{8}$ Denoting the total property tax revenues in city $i$ by $T_{i}$, the nominal property-tax rate by $t_{i}^{n}$, total assessed property value by $A_{i}$, total market property value ("equalized value") by $V_{i}$, the effective tax rate is given by $t_{i}=T_{i} / V_{i}=t_{i}^{n} A_{i} / V_{i}$. Data for this calculation are drawn from the Massachusetts Taxpayers Foundation $(1980,1981)$, and Commonwealth of Massachusetts, Department of Revenue (1980).

${ }^{9}$ Sources are the 1980 and 1990 Census of Population and Housing and the 1982 Census of Governments.

${ }^{10}$ For this outcome to occur, housing expenditure (and hence average house value) must increase less rapidly than the demand for public spending as income rises. With the income elasticity of housing demand often estimated to be near unity, demand for public spending must then be income-inelastic.

${ }^{11}$ Use of a direct poverty measure led to heteroscedastic residuals, which affect the efficiency of the estimates and bias the coefficient standard errors. Another variable that was tried and dropped is the proportion of the population under age 17, which again generated heteroscedastic residuals. This youth variable in addition had a significantly negative coefficient, indicating (counterintuitively) that cities with high education needs have low tax rates. We also experimented with median house value as an explanatory variable, but dropped it because of potential endogeneity (its coefficient was also never statistically significant). Some specifications included the business share of total property value, but this variable had no consistent effect on tax rates.

${ }^{12}$ The results are largely unchanged when the public-sector earnings variable is deleted.

${ }^{13} \mathrm{~A}$ high community growth rate tends to be associated with a peripheral location in a metropolitan area, and thus low population density. However, use of population density in place of the population growth rate led to an equation with heteroscedastic residuals.

${ }^{14}$ Observe that the $\phi$ estimates are uniformly less than unity, as required for $(I-\phi W)$ to be invertible when $W$ is row-normalized (see Anselin (1988)). Although likelihood values are not reported, the equations based on the contiguity matrices $W^{\text {cont }}$ and $W^{\text {Pcont }}$, which aggregate tax rates only across communities that share borders with a given jurisdiction, generate the largest values.

${ }^{15}$ These needs may involve higher spending for public health, police, etc. The poverty-based explanation is supported, however, by the fact that a direct poverty measure also had a positive and significant coefficient. 
${ }^{16}$ Since the city of Boston has by far the highest tax rate in the 1980 sample, we were concerned that the estimated effects of the socio-economic variables depended heavily on the Boston observation. However, when tax rates were regressed on these variables alone (with the spatial lag variable omitted), the results were similar regardless of whether the Boston observation was included or deleted.

${ }^{17}$ Heyndels and Vuchelen (1998) also find a positive population effect. In addition, income has a negative effect on the tax rate, as in the present results.

${ }^{18}$ Note that while the robust test shows the presence of spatial error dependence under the first weighting scheme, the conditional test is only marginally significant.

${ }^{19}$ With population included among the explanatory variables, the experiment described in a footnote 16 yields the same conclusion as before. In other words, even though Boston is an outlier both in terms of tax rate and population, an OLS regression of the tax rate on the above variables yields similar results with and without Boston. Most importantly, the population coefficient remains positive when Boston is omitted.

${ }^{20}$ These gains are calculated by multiplying the increment to the tax base by the previous year's tax rate. This amount plus 2.5 percent of the original tax base equals the permitted increase in the levy.

${ }^{21}$ The levy limit for such cities, which initially equaled 2.5 percent of total property value, exceeded the actual levy. With the levy limit rising slowly per year, the actual levy eventually overtook it in most cases.

${ }^{22}$ Note that a more sophisticated approach would recognize that reaction functions become flat once they encounter the levy-limit constraint. However, implementing this kind of doubleregime specification in a spatial lag context appears difficult.

${ }^{23}$ The results for the various diagnostic tests are similar to those in Table 2. Also, the results are unaffected if the growth-rate variable is deleted.

${ }^{24}$ Business property could not bear more than 150 percent of the burden it would face under uniform taxes, and residential property could not bear less than 65 percent of the burden it would face under uniform taxes. See Bradbury (1988).

${ }^{25}$ This corresponds to an increase from $\$ 7957$ to $\$ 9946$. 